\title{
Article \\ An innovative method of applying fluxes using the low-pressure cold gas spraying method
}

\author{
Tomasz Wojdat ${ }^{1, *}$, Marcin Winnicki $^{1}$, Zbigniew Mirski $^{1}{ }^{1}$, Agata Żuk ${ }^{1}$ \\ 1 Wrocław University of Science and Technology, Poland \\ Marcin Winnicki, Ph.D.; marcin.winnicki@pwr.edu.pl \\ Prof. Zbigniew Mirski, zbigniew.mirski@pwr.edu.pl \\ Agata Żuk, Eng. agata.zuk@pwr.edu.pl \\ * Correspondence: Tomasz Wojdat, Ph.D.; tomasz.wojdat@pwr.edu.pl
}

Received: 10.06.2019; Accepted: 30.09.2019

\begin{abstract}
In the paper, the results of tests of flux application for aluminum brazing processes using the low-presure cold gas spraying method, are presented. It was pointed out that this method could be used as an alternative to current methods of flux application, among others in the production of aluminum heat exchangers. The results of wettability tests made with braze spreading method on fluxed substrates and metallographic investigations of brazed joints are presented. Good quality of brazed joints without incompatibilities and good mechanical properties have been demonstrated.
\end{abstract}

Keywords: applying fluxes; heat exchangers; cold gas spraying; brazing

\section{Introduction}

The use of heat exchangers in the automotive industry dates back to the late 19th century. Since then, commensurably with the development of technology, heat exchangers used in the automotive industry have begun their evolution process. This development is observed both in the plane of materials used in their production and in the technology of their production, mainly using various welding techniques [1]. In addition, the evolution of heat exchangers is determined by a significant increase in the technological advancement of motor vehicles, which creates new areas in which heat exchangers are used, e.g. gearbox oil cooler, engine oil cooler, supercharged air cooler, fuel coolers [1]. Not without significance is the growing ecological and economic awareness of society, forcing manufacturers to use lightweight, easily recyclable construction materials. As a result, currently heat exchangers used in various types of motor vehicles,

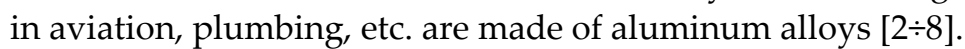

The production of innovative heat exchangers requires the use of highly efficient processes that are able to ensure the achievement of durable, aesthetic joints of good quality and good operational properties, enabling them to work in various, often adverse conditions. The mass production of aluminum heat exchangers mainly uses tunnel furnaces operating in $C A B$ technology (Controlled Atmosphere Brazing), in which nitrogen is the most commonly used inert gas [1]. The use of $C A B$ technology allows achieving much greater line production efficiency and better repeatability than e.g. in a batch furnace. In addition, flame brazing is used in unit production or during the assembly of some heat exchanger components manufactured in the CAB technology [1,9].

The soldering process requires the use of additional materials - binder in the form of solder and very often fluxes, which in some applications can be replaced by a controlled atmosphere, including vacuum [2]. When brazing aluminum heat exchangers, solders are also aluminum alloys, but with a lower melting point relative to the bonded material. This is achieved by adding silicon to aluminum, resulting in Al-Si siluminium solders [1,2]. Currently in the automotive industry, the most commonly used is solder with AlEi7.5 (EN AW4043) hypoeutectic composition, in addition, AlSi10 (EN AW-4045) and AlSi12 (EN AW-4047) alloys with eutectic composition are used, mainly in places where exchanger temperature during soldering is locally lowered [1]. In addition, the process requires the use of a chemically active flux, which is most often the $\mathrm{NOCOLOK}^{\circledR}$ non-corrosive flux (inorganic $\mathrm{KF}_{1-3} \mathrm{AlF}_{4-6}$ fluoride salt) [1,9]. The flux is applied to previously prepared exchangers, assembled in a special tooling, at the initial stage of furnace soldering. The flux is designed to provide good wettability that determines good fill of the solder gap. However, you must follow the rules for the proper application of the appropriate amount. This is particularly important 
because after the brazing process, any residues of post-flux slag deteriorate some of the properties of the exchanger itself. In the case of flux residue on the outer surface of the heat exchanger element involved in heat exchange, the thermal conductivity may deteriorate. Depending on the materials used, the function of the exchanger and the operating environment, the accumulation of more flux slag residues can also be a source of potential corrosion in special cases. There is also a problem of reacting (so-called gelation) of flux residue from the inside of the exchanger with refrigerant inhibitors. This phenomenon consists in flushing flux residues from the inside of the components in the cooling system through the coolant, which can lead to throttling or clogging of one of the heat exchangers from the system - usually with a small cross-sectional area [1]. Currently, the automotive industry is introducing increasingly stringent standards that limit the amount of flux used. It causes that for some applications new solutions and methods of applying flux are being sought, which will ensure strict control of its quantity, which is impossible or very difficult in the case of currently used methods.

Flux application is therefore a very important part of the technological process of manufacturing solder joints. It is especially important in the production of aluminum heat exchangers due to their complicated shape. Currently, the most commonly used methods of applying flux to the surfaces of aluminum heat exchangers are - spraying the flux water suspension, spraying the flux mixture with air using electrostatic phenomena, spraying the flux in the form of paint (water flux suspension with the addition of an adhesive) and applying the flux in the form of a paste (mixture flux and alcohols] [1].

Not in every application, however, the above methods are fully effective or do not provide an effective solution in the light of new, strict regulations on the control of the amount of flux applied. The challenges faced by the industry producing aluminum heat exchangers have become one of the basic reasons for undertaking this research topic. It was decided to explore the possibility of using the method of low-pressure cold gas spraying (LPCS) in the application of flux on the surface of aluminum alloys in the context of its subsequent use in industrial conditions.

This method consists of accelerating compressed and heated gas to supersonic speeds, to which a coating material in the form of powder is fed through a separate wire under the influence of vacuum. The powder mixes with the gas at the point of narrowing of the convergent-divergent de Laval's nozzle. The gas used for spraying can be helium, nitrogen or air at a temperature of $200 \div 650{ }^{\circ} \mathrm{C}$ and a pressure in the range of $0.5 \div 0.9 \mathrm{MPa}$. The connection of powder particles with the substrate occurs at the time of their mutual contact as a result of plastic (adiabatic) deformation resulting from the exchange of their high kinetic energy. The coating is built in a solid state due to the temperature of the powder, which may be close to, but not exceed, the melting point of the parent material. The temperature during spraying is relatively low compared to other thermal spraying methods, which means that the applied layers do not oxidize so much [10].

Due to the low cost of coating production, the method is widely used in repair work on the surface of elements that have changed as a result of corrosion, wear or mechanical damage. This application can be found, among others in the aviation industry. The costs of buying new parts are reduced by restoring the original dimensions of worn elements mainly from aluminum and magnesium, such as gear housing, actuators, etc. [10]. In addition, as stated in papers [11,12], the method also works well in welding processes, especially soldering, materials with different physicochemical and mechanical properties.

\section{Materials and research methodology \\ Basic and additional materials}

Attempts to apply flux by the LPCS method for the brazing process were carried out on an aluminum alloy substrate - EN AW-3003. It is one of the most commonly used alloys used to manufacture most of the heat exchanger components, such as tubes and heat dissipating elements in the form of appropriately shaped tapes [1]. The binder selected was EN AW-4047 (AlSi12) near-eutectic brazing filler metal containing in its chemical composition an addition of approx. $12 \%$ wt. Si. The chemical composition of the binder and the basic material together with their melting temperature are presented in table I [13].

Table I. Chemical composition of the base material and the binder [13]

\begin{tabular}{ccccccccc}
\hline $\begin{array}{c}\text { Alloy } \\
\text { designation }\end{array}$ & Si & Fe & Cu & Mn & Mg & Zn & Al & \multicolumn{2}{c}{ Melting temperature } \\
range, ${ }^{\circ} \mathbf{C}$
\end{tabular}


Flux according to the NOCOLOK ${ }^{\circledR}$ technology in the form of powder with an average particle size in the range of $2 \div 6 \mu \mathrm{m}$ was selected for spraying tests. The activity temperature of the flux is in the range of $567 \div 572{ }^{\circ} \mathrm{C}$. Chemical composition of the flux according to the manufacturer's data is respectively: $28 \div 31 \%$ wt. K, $16 \div 18 \%$ wt. Al, $49 \div 53 \%$ wt. F, max. $2.5 \%$ wt. $\mathrm{LOH}[14]$.

\section{Research methodology}

As mentioned above, attempts have been made to apply flux to aluminum substrates by using low pressure cold gas spraying (LPCS). The flux spraying process was carried out on a low-pressure DYMET 413 device, equipped with a de Laval nozzle gun with an output diameter of $5 \mathrm{~mm}$ and a built-in $10 \mathrm{~kW}$ heater connected to a manipulator working in 3 axes. Before the flux was applied to the substrates that were used for the soldering process, the selection of parameters was carried out consisting in spraying tests for various process variables. Changed among others gas heating temperature, gas pressure and burner feed speed. The value of parameters for which flux was applied for soldering tests are presented in table II, and when selecting them, the adhesion of the flux layer applied to the substrate and its external appearance were assessed.

Table II. Parameters of the NOCOLOK ${ }^{\circledR}$ flux spraying process

\begin{tabular}{ccccc}
\hline Gas pressure & $\begin{array}{c}\text { Gas heating } \\
\text { temperature }\end{array}$ & Torch feed & Nozzle distance & Powder feed rate \\
\hline $5 \mathrm{bar}$ & $200{ }^{\circ} \mathrm{C}$ & $10 \mathrm{~mm} / \mathrm{s}$ & $10 \mathrm{~mm}$ & $8 \mathrm{~g} / \mathrm{min}$ \\
\hline
\end{tabular}

Figure 1 shows a cross-sectional view of the applied flux layer on an aluminum substrate. The average thickness of the flux layer applied was $5 \mu \mathrm{m}$. Since the flux layer has a dark color similar to the background color (Fig. 1a), the range of its occurrence is marked in yellow in figure $1 \mathrm{~b}$.

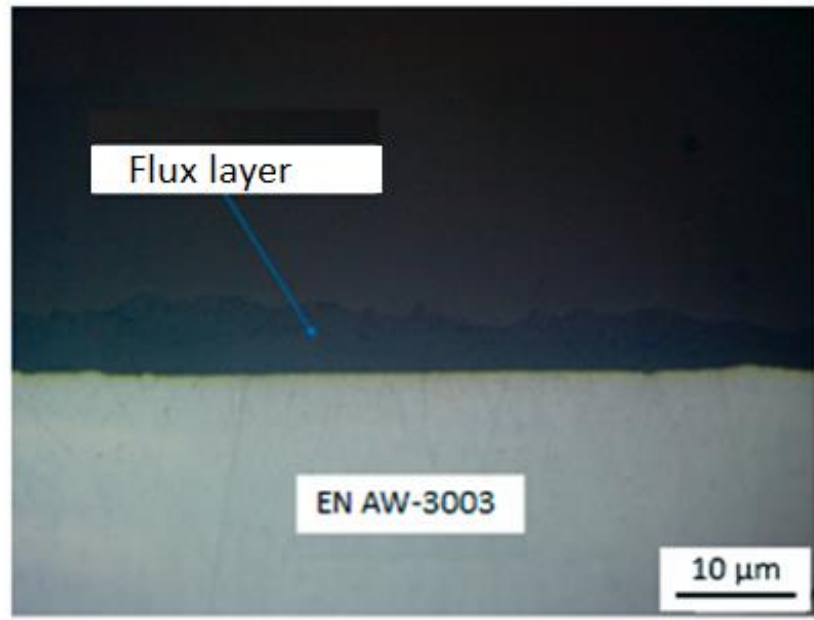

(a)

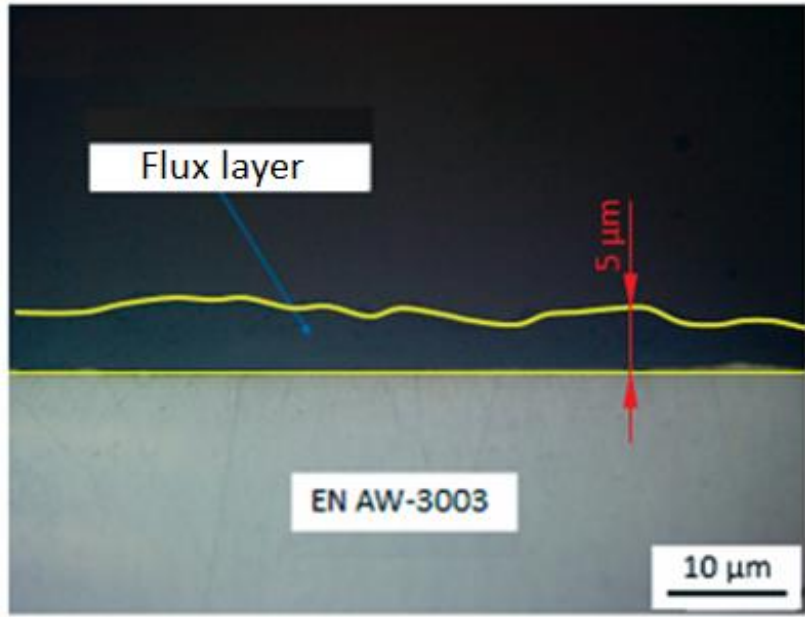

(b)

Fig. 1. NOCOLOK ${ }^{\circledR}$ flux layer applied to EN AW-3003 alloy substrate by means of LPCS method

The flux was applied to two types of $30 \times 30 \mathrm{~mm}$ samples used for wettability tests and $25 \times 80 \mathrm{~mm}$ samples, which were used to make lap joints. For the latter, flux was applied to only one end of the sample to a width of $10 \mathrm{~mm}$, which corresponded to the length of the overlap. A constant braze gap width of $0.2 \mathrm{~mm}$ was used, which was determined using steel spacers. Brazing tests were carried out in a resistance heated furnace using an additional nitrogen blanket atmosphere, just like in real industrial brazing conditions in CAB tunnel furnaces. Samples placed on a ceramic support were put into an oven heated to $600{ }^{\circ} \mathrm{C}$, brazing time due to the high thermal inertia of the samples was 5 minutes. After the brazing time elapsed, the heating was turned off, the furnace chamber was opened, leaving the samples to reach the ambient temperature. Then, flux residues were removed from them under running water, dried and prepared for further metallographic and mechanical tests. For comparative purposes, the same samples were also made, except that the $\mathrm{NOCOLOK}^{\circledR}$ flux was applied in the form of a paste. 


\section{Research results and discussion}

\section{Tests of flowability and wettability}

The effectiveness of the applied flux layer on the possibility of correct brazing process was assessed by the flow method, which is a measure of the ability of the liquid binder to spread in any directions on the surface of the material. The flowability and wettability largely depend on the physicochemical properties of the braze itself, the base material and the size of the adhesive forces, and both properties are closely related.

The flowability is determined on the basis of the planed surface of the solder flow - Ks coefficient (1), as well as the thickness of the solder layer after melting $-K_{H}$ coefficient (3).

- The Ks coefficient is determined from the formula:

$$
K_{s}=\frac{A_{s r}-A_{o}}{A_{o}}
$$

Where:

Ks - braze dissolution coefficient,

$A_{s i r}$ - average braze surface area,

$A_{o}$ - surface of the flat projection of the spherical braze sample with the volume $\mathrm{V}$ on ground plane, calculated from the formula (2):

$$
A_{o}=\left[\frac{3}{4} \cdot \pi \cdot V\right]^{\frac{2}{3}}
$$

- And the $K_{H}$ coefficient is equal:

where:

$$
K_{H}=\frac{D-H_{s} r}{D} \cdot 100 \%
$$

$K_{H}$ - melted braze layer thickness coefficient,

$H_{s i}$ - average thickness of the molten braze layer,

$D$ - theoretical diameter of a spherical braze sample with a volume of $\mathrm{V}$, in the absence of wetting, calculated from formula (4).

$$
D=1,2 \cdot V^{\frac{1}{3}}
$$

Good braze flow is assumed when the value of $K_{H}>70 \%$. In the case of the $K_{s}$ coefficient, the average absolute value of the real molten braze surface $\left(A_{s r}-A_{o}\right)$ is obtained in relation to the material surface obscured by the projection of the braze sample.

The results of the flow and wettability tests are presented in table III, while figure 2 shows examples of contact angles. In the case of samples where flux was applied by LPCS method, $0.1 \mathrm{~g}$ braze was laid and then put into the furnace. However, in reference samples where flux in the form of a paste was used, its amount was equal to half the weight of the braze.

Table III. Results of tests of the flow and wettability of the EN AW-4047 braze depending on the method of flux application

\begin{tabular}{cccccccccc}
\hline $\begin{array}{c}\text { Flux application } \\
\text { method }\end{array}$ & $\begin{array}{c}\text { Substrate } \\
\text { type }\end{array}$ & $\begin{array}{c}A_{s r} \\
{\left[\mathbf{m m}^{2}\right]}\end{array}$ & $\begin{array}{c}\sigma_{A} \\
{\left[\mathbf{m m}^{2}\right]}\end{array}$ & $\boldsymbol{K}_{s}$ & $\begin{array}{c}\boldsymbol{H}_{s r} \\
{[\mathbf{m m}]}\end{array}$ & $\begin{array}{c}\sigma_{H} \\
{[\mathbf{m m}]}\end{array}$ & $\begin{array}{c}\boldsymbol{K}_{H} \\
{[\%]}\end{array}$ & $\boldsymbol{\theta}_{s r}\left[{ }^{\circ}\right]$ & $\sigma_{\theta}\left[^{\circ}\right]$ \\
\hline LPCS & \multirow{2}{*}{ EN AW-3003 } & 129.8 & 8.4 & 6.4 & 0.29 & 0.015 & 92.3 & 9.6 & 3 \\
Paste & 137.5 & 12.7 & 6.8 & 0.23 & 0.014 & 93.9 & 8.1 & 2.5 \\
\hline
\end{tabular}

${ }^{1} A_{s i r}$ - average surface area of braze dissolution (from 5 measurements); $\sigma_{A}, \sigma_{H}$ - standard deviation;

$A_{o}=17.6 \mathrm{~mm}^{2}, H_{s r}$ - average braze layer thickness (from 5 measurements); $D=3.8 \mathrm{~mm}$.

${ }^{2} \theta_{s r}$ - average contact angle value (from 5 measurements); $\sigma_{\theta}-$ standard deviation. 


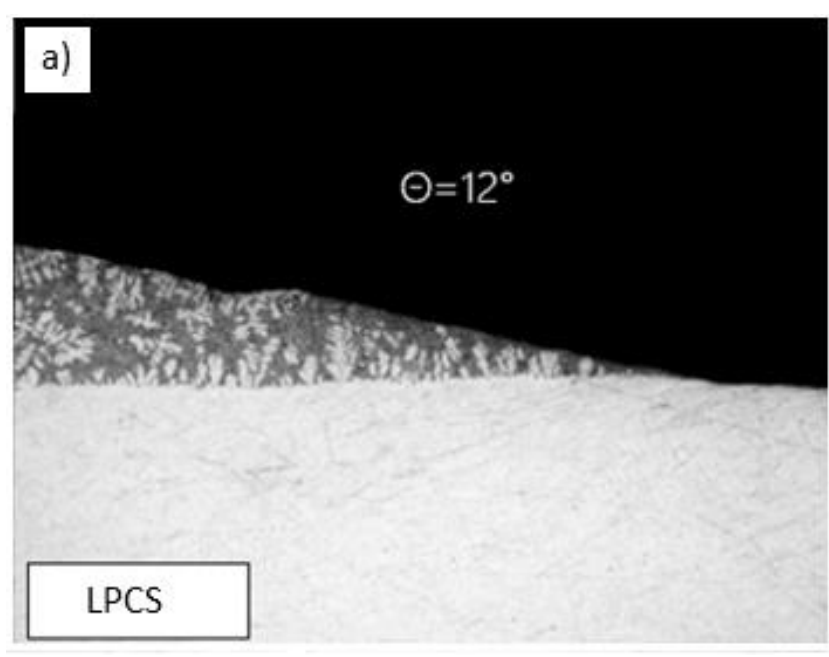

(a)

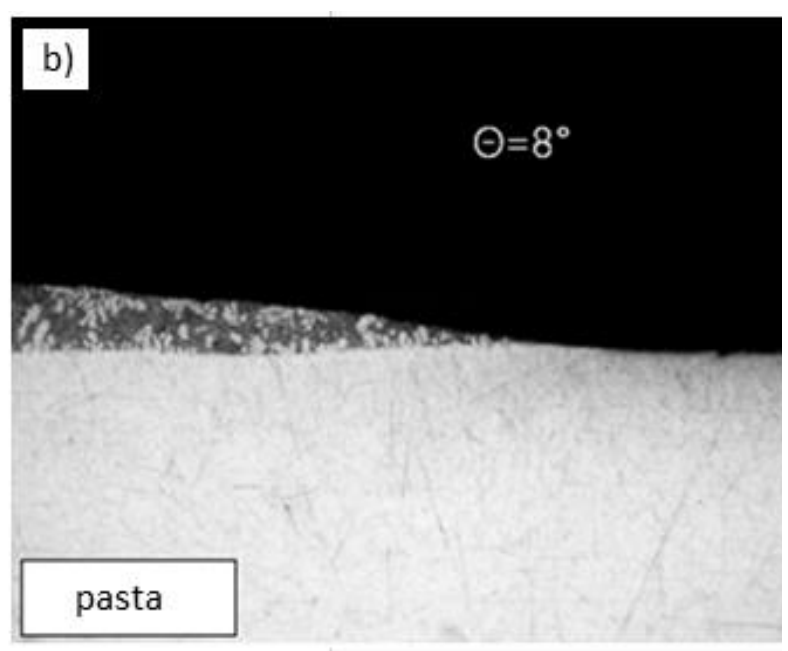

(b)

Fig. 2. Exemplary values of contact angle of aluminum substrate with EN AW-4047 braze for flux applied a) by LPCS and $b$ ) in the form of paste

The obtained results clearly confirm the possibility of using the LPCS method for applying fluxes for brazing processes. This is demonstrated, for example, by very good wettability, where the average contact angle is below $10^{\circ}$ and is within the statistical error limit of test results obtained for fluxes applied in a conventional manner. It can therefore be presumed that this method is as effective as the methods currently used in the industry that produces aluminum heat exchangers for the automotive industry.

\section{Metallographic tests}

Metallographic tests were carried out only using light microscopy, as they were intended to identify possible brazing discrepancies occurring in brazed joints. For microscopic examination, solder joints were cut in half the width of the overlap and included in epoxy resin. Observations were made on ground and polished metallographic specimens.

None of the analyzed joints found any brazing incompatibilities that could have a negative impact on their operational properties. The brazing gap in all three cases was correctly filled with braze over the entire length of the joint. The formed braze is characteristic of near-eutectic silumin filler metal (Fig. 3). It shows dendrites of the $\alpha(1)$ solution, spreading towards its center from the diffusion zone occurring at the border with native materials (2), distributed in the eutectic mixture $(\alpha+\mathrm{Si})(3)$.

The flux applied to the EN AW-3003 aluminum alloy substrate creates good conditions for creating brazes with good quality, high aesthetics and most importantly without brazing incompatibilities.

\section{Tests of mechanical properties}

Before the static shearing test, excess of the braze was mechanically removed. The dimensions of the overlap in each case were approximately $10 \times 25 \mathrm{~mm}$. A static tensile shear test was carried out on a testing machine with a hydraulic drive for a crossbeam speed of $2 \mathrm{~mm} / \mathrm{min}$. Six test joints were prepared for the tests, prepared for flux applied by the LPCS method and for flux in the form of paste applied manually on brazeable substrates.

For such a large overlap surface, the destruction occurred in the native material, except for the lap joint. The tensile strength of the parent material was less than $120 \mathrm{MPa}$. It was decided to halve the length of the overlap (up to $5 \mathrm{~mm}$ ), but this solution also did not bring the expected effect and the scrap was still located in the native material. The expected result, i.e. destruction in the lap joint, was obtained by reducing the overlap length to $2 \mathrm{~mm}$. However, the fracture did not occur in the braze as a result of its decoherence, but as a result of being pulled out of the native material in the diffusion zone (Fig. 4).

All results were similar (Table IV) and were slightly lower than the tensile strength of the native material, which according to the standard is $135 \mathrm{MPa}$. In the case of joints made using LPSC flux applied, shear strength was in the range of $116 \div 120 \mathrm{MPa}$, and similarly in the case of joints in which flux in the form of paste was applied: $114 \div 124 \mathrm{MPa}$. 

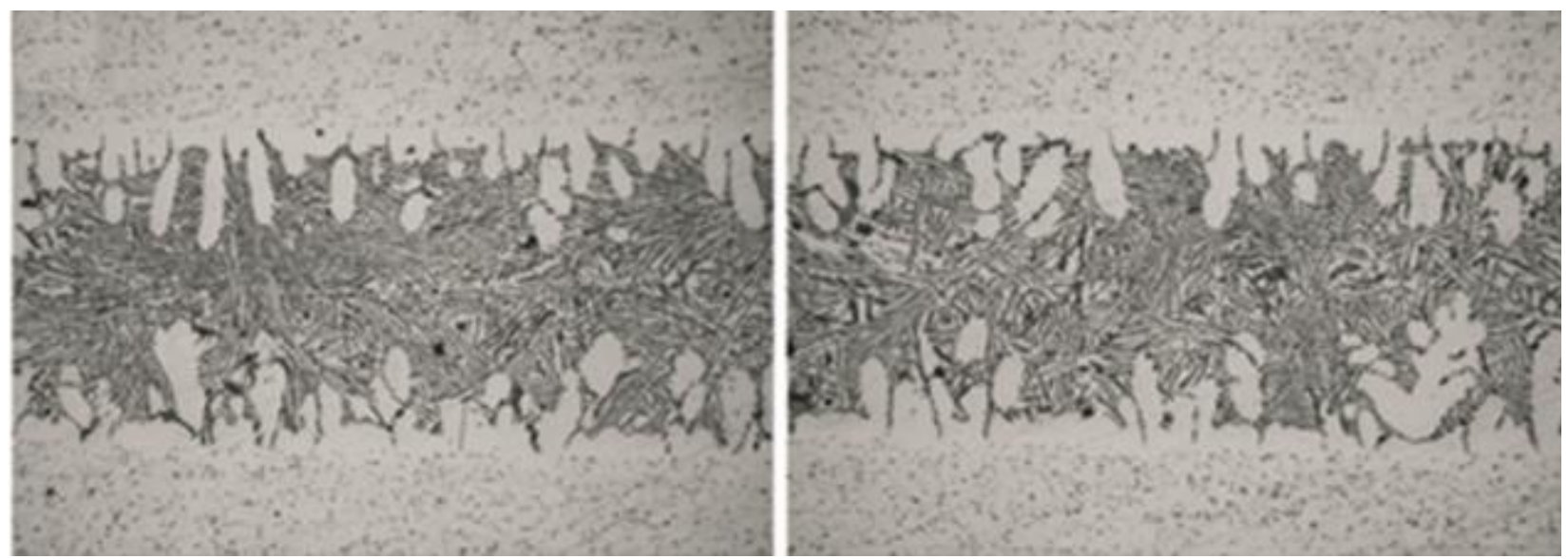

(a)
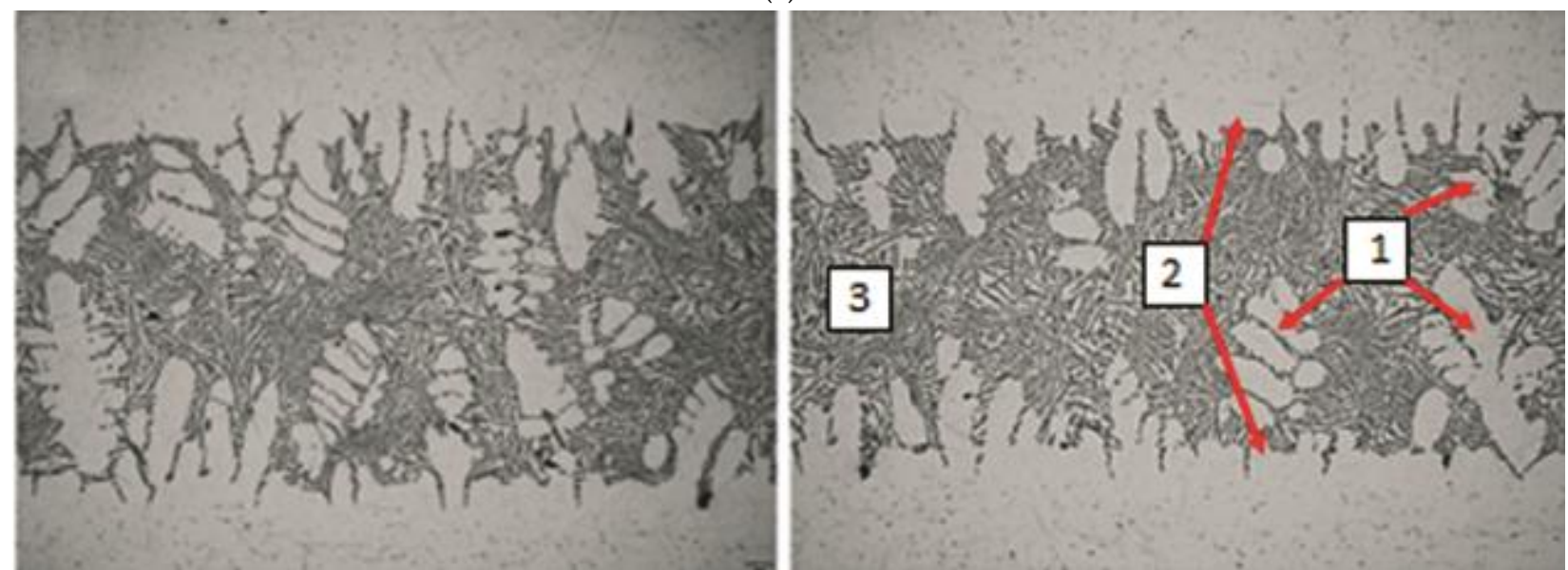

(b)
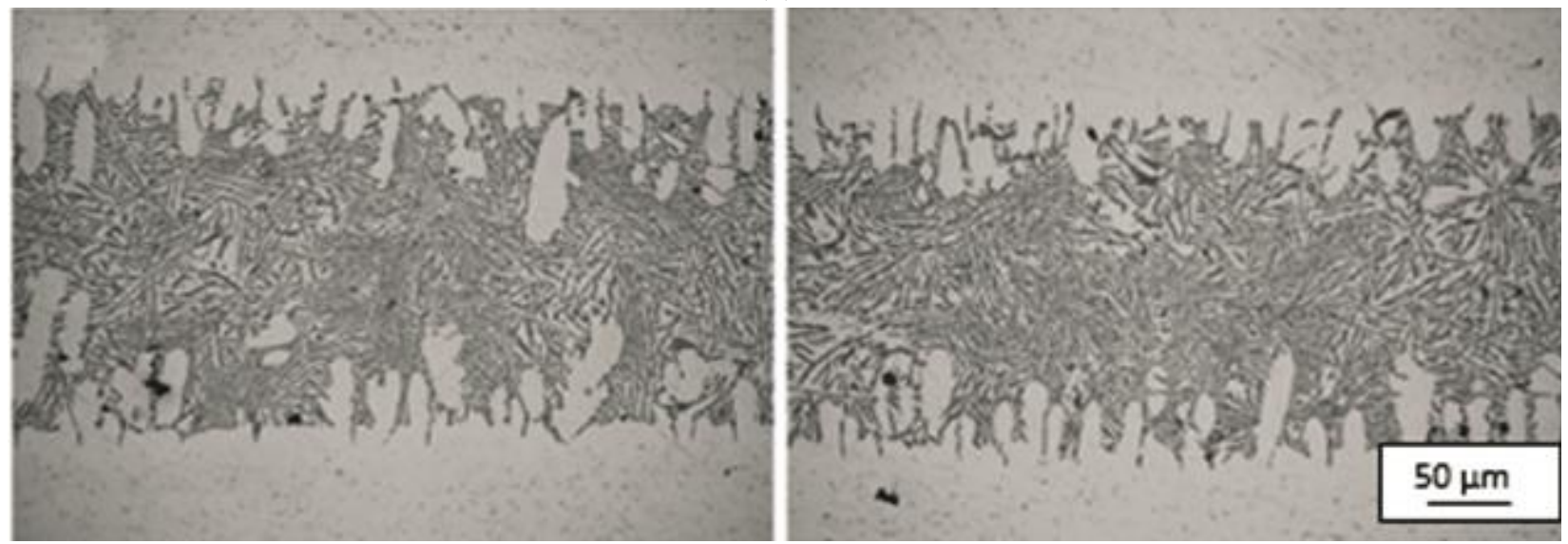

(c)

Fig. 3. Brazed joints of aluminum alloy EN AW-3003, made for flux applied by LPCS method: a) joint No. 1, b) joint No. 2, c) and joint No. 3; 1 - dendrites of solid $\alpha$ solution, 2 - diffusion zones, 3 - eutectics $(\alpha+\mathrm{Si})$

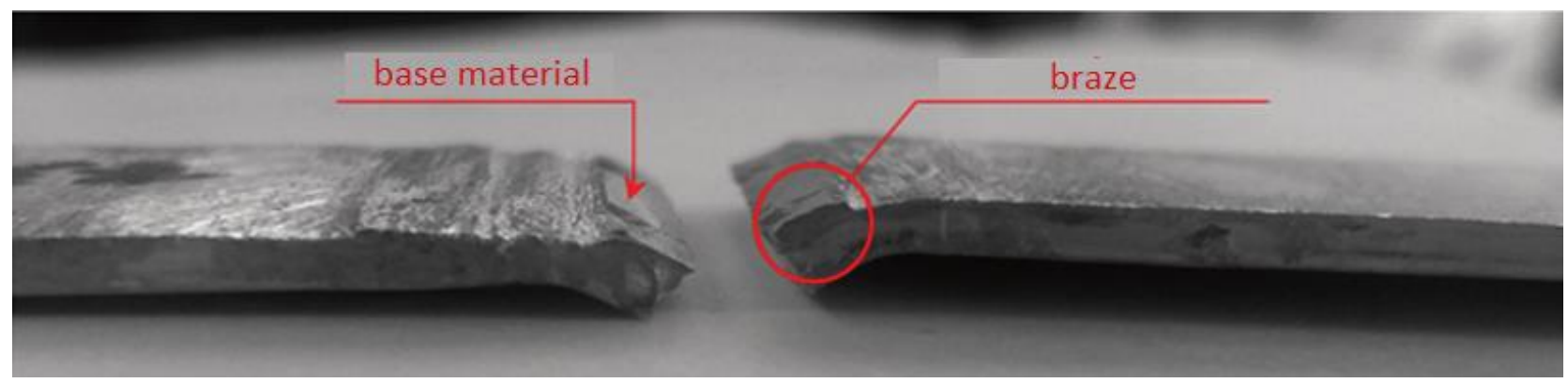

Fig. 4. An example of a brazed joint fracture for an overlap length of $2 \mathrm{~mm}$ 
Table IV. Results of static shear test during stretching of brazed joints

\begin{tabular}{|c|c|c|c|c|c|c|}
\hline $\begin{array}{c}\text { Sample } \\
\text { No. }\end{array}$ & Flux & $\begin{array}{c}\text { Overlap } \\
\text { dimensions } \\
{[\mathrm{mm}]}\end{array}$ & $\begin{array}{c}\text { Surface area } \\
\qquad\left[\mathrm{mm}^{2}\right]\end{array}$ & $\begin{array}{c}\text { Destructive } \\
\text { force } \\
{[\mathrm{N}]} \\
\end{array}$ & $\begin{array}{c}\text { Tensile/shear } \\
\text { strength } \\
\left(\mathbf{R}_{\mathrm{m}} / \mathbf{R}_{\mathrm{t}}\right)[\mathrm{MPa}]\end{array}$ & $\begin{array}{c}\text { Fracture } \\
\text { area }\end{array}$ \\
\hline 1.1 & \multirow{6}{*}{ LPCS } & $10 \times 25$ & 250 & 30200 & 120.8 & NM \\
\hline 1.2 & & $5 \times 25$ & 125 & 14800 & 118.4 & NM \\
\hline 1.3 & & $2 \times 25$ & 50 & 6000 & 120.0 & $\mathrm{~J}-\mathrm{DZ}$ \\
\hline 1.4 & & $2 \times 25$ & 50 & 5800 & 116.0 & J-DZ \\
\hline 1.5 & & $2 \times 25$ & 50 & 6100 & 122.0 & J-DZ \\
\hline 1.6 & & $2 \times 25$ & 50 & 6000 & 120.0 & J-DZ \\
\hline 2.1 & \multirow{6}{*}{ Paste } & $10 \times 25$ & 250 & 29900 & 119.6 & NM \\
\hline 2.2 & & $5 \times 25$ & 125 & 15200 & 121.6 & NM \\
\hline 2.3 & & $2 \times 25$ & 50 & 5700 & 114.0 & J-DZ \\
\hline 2.4 & & $2 \times 25$ & 50 & 6200 & 124.0 & $\mathrm{~J}-\mathrm{DZ}$ \\
\hline 2.5 & & $2 \times 25$ & 50 & 6000 & 120.0 & J-DZ \\
\hline 2.6 & & $2 \times 25$ & 50 & 5900 & 118.0 & J-DZ \\
\hline
\end{tabular}

Notes: NM - native material, J-DZ - joint - diffusion zone

Hardness measurements were also made using the Vickers method at a penetrator load of $50 \mathrm{G}$. The hardness distribution was characteristic for individual joint zones, i.e. braze was harder, on average 75.3 HV0.05 with a noticeable slight increase in hardness in the diffusion zone to values in the range of $80.2 \div 84.8$ HV0.05. The average hardness of the native material was 53.6 HV0.05.

\section{Conclusions}

The research experiment carried out, the results of which are presented in the article, clearly shows that the use of the method of low-pressure cold gas spraying (LPCS) in the process of applying brazing flux is very effective. The use of the LPCS method is advantageous in the light of new, more stringent regulations in force in the automotive industry regarding the amount of flux used, because it allows to accurately control this parameter. In addition, another important aspect is the ability to apply flux in hard to reach places. The flux applied by LPCS effectively performs its role and works well in the brazing process of aluminum alloys, providing good brazing properties for the filler metal, which in turn enables the production of durable and functional braze joints. It is a method that provides similar efficiency in relation to the quality of connections obtained as currently used in industrial conditions methods of flux application. In the LPCS spraying process, the results obtained are influenced by a lot of different process variables that can be changed in a wide range, thus adapting, among others the amount of flux for specific requirements and industrial applications. However, it should be emphasized that the application of this method in industrial conditions may be significantly limited at the moment and requires a series of optimization tests.

Author Contributions: For research articles with several authors, a short paragraph specifying their individual contributions must be provided. The following statements should be used "conceptualization, T.W. and M.W.; methodology, T.W.; software, M.W.; validation, Z.M., A.Z.; formal analysis, Z.M.; investigation, A.Z.; resources, T.W.; data curation, M.W.; writing-original draft preparation, T.W.; writing-review and editing, M.W.; visualization, A.Z.; supervision, Z.M.; project administration, M.W.; funding acquisition, T.W.", Authorship must be limited to those who have contributed substantially to the work reported.

Conflicts of Interest: The authors declare no conflict of interest.

\section{References}

[1] Mirski Z., Pabian J., Modern trends in production of brazed heat exchangers for automotive industry, Welding Technology Review, 2017, Vol. 89(8), 5-12. [CrossRef]

[2] Davis J.R., Aluminum and aluminum alloys, 2003, ASM International. 
[3] Burger G.B., Gupta A.K., Jeffrey P.W., Lloyd D.J., Microstructural control of aluminum sheet used in automotive applications, Materials Characterization, 1995, Vol. 35(1), 23-39. [CrossRef]

[4] Cole G.S., Sherman A.M., Lightweight materials for automotive applications. Materials Characterization, 1995, Vol. 35(1), 3-9. [CrossRef]

[5] Immarigeon J.-P., Holt R.T., Koul A.K., Zhao L., Wallace W., Beddoes J.C., Lightweight materials for aircraft applications, Materials Characterization, 1995, Vol. 35(1), 41-67. [CrossRef]

[6] Nakai M., Eto T., New aspect of development of high strength aluminum alloys for aerospace applications, Materials Science and Engineering, 2000, Vol. 285(1), 62-68. [CrossRef]

[7] Mehta D.S., Masood S.H., Song W.Q., Investigation of wear properties of magnesium and aluminum alloys for automotive applications, Journal of Materials Processing Technology, 2004, Vol.155-156, 1526-1531.

[CrossRef]

[8] Starke E.A. Jr., Staley J.T., Application of modern aluminum alloys to aircraft, Progress in Aerospace Sciences, 1996, Vol. 32(2-3), 131-172. [CrossRef]

[9] Frąckowiak E., Mroziński, Using flame brazing technology for producing aluminium automotive heat exchangers, Welding Technology Review, 2007, Vol. 79(9), 57-62.

[10] Klinkov S.V., Kosarev V.F., Rein M., Cold spray deposition: Significance of particle impact phenomena, Aerospace Science and Technology, 2005, Vol. 9, 582-591. [CrossRef]

[11] Wojdat T., Winnicki M., Rutkowska-Gorczyca, Mirski Z., Ambroziak A., Soldering aluminium to copper with the use of interlayers deposited by cold spraying, Archives of Civil and Mechanical Engeneering, 2016, Vol.16(4) 835-844. [CrossRef]

[12] Wojdat T., Winnicki M., Łamasz S., Żuk A., Application of interlayers in the soldering process of graphite composite with aluminum alloy 6060, Archives of Civil and Mechanical Engineering, 2019, Vol. 19(1), 91-99. [CrossRef]

[13] PN EN 573-1 Aluminium i stopy aluminium - Skład chemiczny i rodzaje wyrobów przerobionych plastycznie Część 1: System oznaczeń numerycznych.

[14] Solvay Flux GmbH: The NOCOLOK® Flux Brazing Process, http://www.solvay.com/en/binaries

(C) 2019 by the authors. Submitted for possible open access publication under the terms and conditions of the Creative Commons Attribution (CC BY) license (http://creativecommons.org/licenses/by/4.0/). 